\title{
Effects of Morin on the Bioavailability of Doxorubicin for Oral Delivery in Rats
}

\author{
Hong-Mook Son and Jun-Shik Choi ${ }^{\dagger}$
}

\author{
College of Pharmacy, Chosun University, Gwangju 501-759, Republic of Korea
}

(Received March 25, $2009 \cdot$ Revised March 31, 2009 • Accepted July 30, 2009)

\begin{abstract}
The purpose of this study was to investigate the effects of morin, an antioxidant, on the bioavailability of doxorubicin (DOX) in rats. Thus, DOX was administered intravenously $(10 \mathrm{mg} / \mathrm{kg})$ or orally $(50 \mathrm{mg} / \mathrm{kg})$ with or without oral morin $(0.5,3$ and $10 \mathrm{mg} / \mathrm{kg})$. In the presence of morin, the total area under the plasma concentration-time curve (AUC) of DOX was significantly greater than that of the control. In the presence of 3 and $10 \mathrm{mg} / \mathrm{kg}$ of morin, the peak concentration $\left(\mathrm{C}_{\max }\right)$ was significantly higher than that of the control. Consequently, the absolute bioavailability (AB) of DOX in the presence of morin was $3.7-8.3 \%$, which was significantly enhanced compared with those of the control group (2.7\%). The relative bioavailability (RB) of DOX was 1.36 to 3.02 times higher than those of the control group. Compared to the intravenous control, the presence of morin increased the AUC of DOX, but was not significantly affected. The enhanced bioavailability of oral DOX by oral morin may be due to the inhibition of both P-glycoprotein (P-gp) and cytochrome P450 (CYP) 3A in the intestine and/or liver by morin. This result may suggest that the development of oral DOX combination with morin is feasible, which is more convenient than the i.v. dosage forms. The present study raised the awareness about the potential drug interactions by concomitant use of DOX with morin.
\end{abstract}

Key words - Bioavailability, Pharmacokinetic, Doxorubicin, Morin, P-gp, CYP, Rat

Many researchers have attempted to circumvent the problem through inhibition of P-glycoprotein (P-gp) during cytotoxic drug administration. For example, verapamil, cyclosporine, valspodar, GF120918 or LY357739 have previously been used to enhance intracellular drug accumulation into the MDR cells. ${ }^{1,2)} \mathrm{P}-\mathrm{gp}$, an important member of ABC family, is highly expressed in solid tumors of epithelial origin, such as the colon, ${ }^{3)}$ kidney, ${ }^{4)}$ and breast ${ }^{5)}$ to efflux substrates out of cells. Cytochrome P450 (CYP) 3A, a major phase I drug metabolizing enzyme, are co-localized in the liver and intestine. ${ }^{6,7)}$ Thus, a combined role of P-gp and CYP3A could decrease oral bioavailability of drugs which are substrates of P-gp and CYP3A.

Doxorubicin (DOX) is an anthracycline glycoside anticancer drug with a mechanism of impairing DNA synthesis during tumor cell division. It is most commonly used for the treatment of lymphoma, osteosarcoma and other sarcomas, carcinomas, and melanoma. ${ }^{8-12)}$ DOX is a substrate of P-gp, ${ }^{13)}$ and one or more enzymes of the CYP3A subfamily play a role in DOX metabolism. ${ }^{14)}$

Flavonoids are the most abundant polyphenolic compounds present in the human diet, such as fruits, vegetables, tea, and red wine. Flavonoids have a variety of beneficial pharma-

†본 논문에 관한 문의는 이 저자에게로

Tel : 062)230-6365, E-mail : jsachoi@chosun.ac.kr cological properties, including antitumor, antioxidation, antiviral, and anti-inflammatory activities. ${ }^{15)}$ On the other hand, flavonoids were reported to modulate CYP3A4 and/or P-gp. ${ }^{16-18)}$

Morin (3, 5, 7, 2', 4'-pentahydroxyflavone) is a flavonoid constituent of many herbs and fruits. In vitro studies morin has a variety of beneficial activities, including antioxidation, ${ }^{19)}$ anti-mutagenesis $^{20)}$ and anti-inflammation. ${ }^{21)}$ Like its isomer quercetin, orally administered morin is absorbed easily in the intestine of rodents but it is mainly metabolized as glucuronides and sulfates. ${ }^{22,23)}$ A previous study showed that morin inhibited P-gp mediated cellular efflux of P-gp substrates. ${ }^{24)}$ Buening et $a .^{25)}$ also reported that morin could inhibit cytochrome P-450 reductase in human liver microsomes. This implied that morin might affect the absorption, metabolism and elimination of DOX. Morin significantly increased the area under the plasma concentration-time curve (AUC) of paclitaxel, etoposide and tamoxifen in rats, which might be due to the inhibition of P-gp efflux and CYP3A metabolism in the intestine. ${ }^{26-28)}$ Furthermore, morin and anticancer agents could be prescribed concomitantly for improving cancer therapy, because the morin has beneficial effect such as anticancer and antioxidant activity.

Therefore, the aim of this study was to examine the bioavailability and pharmacokinetics of DOX after the oral or intravenous administration of DOX with morin in rats. 


\section{Materials and Methods}

\section{Materials}

DOX were obtained from Boryung Co. (Seoul, Republic of Korea), morin and daunorubicin [an internal standard for the high-performance liquid chromatographic (HPLC) analysis of DOX] were purchased from Sigma-Aldrich Co. (St. Louis, MO). Other chemicals were of reagent grade and HPLC grade.

\section{Animals}

Male Sprague-Dawley rats, 7-8 weeks old and weighing 270-300 g, purchased from the Dae Han Laboratory Animal Research Company (EumSung, Republic of Korea) were given free access to a commercial rat chow diet (No. 322-7-1; Superfeed Company, Wonju, Republic of Korea) and tap water ad libitum. They were maintained in a clean room (College of Pharmacy, Chosun University) at a temperature of $22 \pm 2^{\circ} \mathrm{C}$ with 12-h light and dark cycles and a relative humidity of 50 $60 \%$. The rats were acclimated under these conditions for at least 1 week. The all protocol of this animal study was approved by the Animal Care Committee of the Chosun University (Gwangju, Republic of Korea). Each rat was fasted for at least $24 \mathrm{~h}$ prior to beginning of the experiment. The left femoral artery (for blood sampling) and the left femoral vein (for drug administration only for intravenous study) were cannulated using a polyethylene tube (SP45; i.d., $0.58 \mathrm{~mm}$, o.d., 0.96 $\mathrm{mm}$; Natsume Seisakusho Company, Tokyo, Japan) while each rat was under light ether anesthesia.

\section{Intravenous and Oral Administration of DOX}

Rats were divided into two groups $(n=6$, each); oral group [50 $\mathrm{mg}(5 \mathrm{~mL}) / \mathrm{kg}$ of DOX dissolved in a distilled water] without (control) or with $0.5,3$ and $10 \mathrm{mg} / \mathrm{kg}$ of oral morin (mixed in distilled water; total oral volume of $3.0 \mathrm{~mL} / \mathrm{kg}$ ), and intravenous group $(10 \mathrm{mg} / \mathrm{kg}$ of DOX dissolved in $0.9 \% \mathrm{NaCl}$ solution; total injection volume of $1.5 \mathrm{~mL} / \mathrm{kg}$ ). A feeding tube was used to administer DOX and morin orally. Morin was administered $30 \mathrm{~min}$ prior to oral administration of DOX. A blood sample $(0.45 \mathrm{~mL})$ was collected into heparinized tubes via the femoral artery at 0 (control), 0.017 (at the end of infusion), $0.1,0.25,0.5,1,2,3,4,6,8,12$ and $24 \mathrm{~h}$ for intravenous study, and $0,0.1,0.25,0.5,1,2,3,5,6,8,12$ and $24 \mathrm{~h}$ for oral study. A whole blood (approximately $1 \mathrm{~mL}$ ) collected from untreated rats was infused via the femoral artery at $0.25,1,3$, 8 and $12 \mathrm{~h}$, respectively, to replace blood-loss due to blood sampling. The blood samples were centrifuged $(13,000 \mathrm{rpm}, 5$ $\min$ ), and a $200 \mu \mathrm{L}$ aliquot of plasma samples was stored at $-40^{\circ} \mathrm{C}$ until the HPLC analysis.

\section{HPLC Analysis of DOX}

The HPLC assay of Andersen et al. ${ }^{29)}$ was used to analyze DOX levels, with minor modifications. Briefly, a $50 \mu \mathrm{L}$ aliquot of daunorubicin $(1 \mu \mathrm{g} / \mathrm{mL}$; internal standard), and a $1 \mathrm{~mL}$ aliquot of acetonitrile was added to each $200 \mu \mathrm{l}$ sample to precipitate proteins and extract DOX. The mixture was then stirred for $2 \mathrm{~min}$ and centrifuged (13,000 rpm, $10 \mathrm{~min})$. A 0.8 $\mathrm{mL}$ aliquot of the upper layer was transferred to another clean microtube, and then evaporated under a gentle stream of nitrogen gas at $38^{\circ} \mathrm{C}$. The residue was reconstituted in $200 \mu \mathrm{L}$ mobile phase prior to injection into a $\mathrm{C}_{18}$ reverse phase column (ODS ThermoHypersil, $4.6 \mathrm{~mm}$, i.d. $\times 150 \mathrm{~mm}, 5.0 \mu \mathrm{m}$, Thermo Electron Co., USA). The mobile phase consisted of $20 \mathrm{mM}$ phosphate buffer ( $\mathrm{pH}$ 3.8):acetonitrile:methanol (45:20 $: 35 ; \mathrm{v} / \mathrm{v} / \mathrm{v}$ ). The flow rate of the mobile phase was $1.0 \mathrm{~mL} / \mathrm{min}$ and the column eluent was monitored using a fluorescence detector at an excitation wavelength of $460 \mathrm{~nm}$ with an emission cut-off filter of $580 \mathrm{~nm}$. The retention times of DOX and daunorubicin (an internal standard) were approximately 3.5 and $5.8 \mathrm{~min}$, respectively. The detection limit of DOX in rat's plasma was $2 \mathrm{ng} / \mathrm{mL}$. The intra- and inter-day variation coefficients of DOX were below $11.3 \%$.

\section{Pharmacokinetic Analysis}

The following pharmacokinetic data were analyzed using the non-compartmental method (WinNonlin software version 4.1; Pharsight Corporation, Mountain View, CA, USA). The halflife $\left(t_{1 / 2}\right)$ was calculated by $0.693 / K_{\mathrm{el}}$. The peak concentration $\left(\mathrm{C}_{\max }\right)$ and the time to reach peak concentration $\left(\mathrm{T}_{\max }\right)$ of DOX directly read from the experimental data. The area under the plasma concentration-time curve $\left(\mathrm{AUC}_{0-\mathrm{t}}\right)$ from time zero to the time of last measured concentration $\left(\mathrm{C}_{\text {last }}\right)$ was calculated by the linear trapezoidal rule. The AUC zero to infinite $\left(\mathrm{AUC}_{0-\infty}\right)$ was obtained by the addition of $\mathrm{AUC}_{0-\mathrm{t}}$ and the extrapolated area was determined by $\mathrm{C}_{\text {last }} / \mathrm{K}_{\mathrm{el}}$. The total body clearance for intravenous $\left(\mathrm{CL}_{t}\right)$ was calculated from the quotient of the dose (D) and $\mathrm{AUC}_{0-\infty}$. The absolute bioavailability (AB) was calculated by $\mathrm{AUC}_{\text {oral }} / \mathrm{AUC}_{\mathrm{IV}} \times$ Dose $_{\mathrm{IV}} /$ Dose $_{\text {oral }} \times 100$, and the relative bioavailability (RB) was estimated by $\mathrm{AUC}_{\text {with morin }}$ / $\mathrm{AUC}_{\text {control }} \times 100$.

\section{Statistical Analysis}

A $p$-value $<0.05$ was deemed to be statistically significant using a Duncan's multiple range test of Statistical Package of Social Sciences (SPSS) posteriori analysis of variance (ANOVA) program among the three means for the unpaired data. All data are expressed as mean \pm standard deviation. 


\section{Results}

\section{Pharmacokinetic Parameters of Oral DOX}

The mean plasma concentration-time profiles of DOX following oral administration to rats in the presence or absence of oral morin are illustrated in Fig. 1. The mean pharmacokinetic parameters of DOX are also listed in Table I. As shown in Table I, the presence of morin significantly altered the pharmacokinetic parameters of DOX. Compared with the control group (given oral DOX alone), the presence of morin significantly increased the area under the plasma concentration time curve from zero to time infinity (AUC) $(\mathrm{P}<0.05$ at 0.5 $\mathrm{mg} / \mathrm{kg} ; \mathrm{P}<0.01$ at 3 and $10 \mathrm{mg} / \mathrm{kg}$ ) and the peak concentration $\left(\mathrm{C}_{\max }\right)(\mathrm{P}<0.05$ at $3 \mathrm{mg} / \mathrm{kg} ; \mathrm{P}<0.01$ at $10 \mathrm{mg} / \mathrm{kg})$ of $\mathrm{DOX}$ by

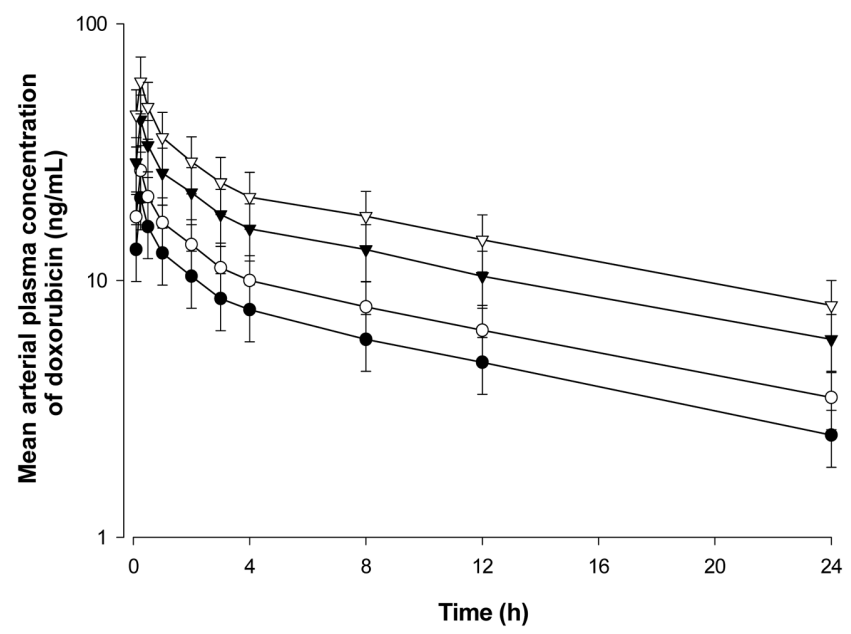

Figure 1-Mean arterial plasma concentration-time profiles of DOX after oral administration of DOX at a dose of $50 \mathrm{mg} / \mathrm{kg}$ in the presence of morin at doses of $0.5(\bigcirc ; n=6), 3(\nabla ; n=6)$ and $10 \mathrm{mg} / \mathrm{kg}$ $(\nabla ; n=6)$ or absence $(O ; n=6)$ of morin to rats. Bars represent stnandard deviation.
$36.1-202 \%$ and $101-183 \%$, respectively. The absolute bioavailability (AB) of DOX was significantly elevated $(\mathrm{P}<0.05$ at $0.5 \mathrm{mg} / \mathrm{kg} ; \mathrm{P}<0.01$ at 3 and $10 \mathrm{mg} / \mathrm{kg}$ ) by $3.7-8.3 \%$, compared with the control group $(2.7 \%)$. The relative bioavailability (RB) of DOX in the presence of morin $(0.5,3$ and 10 $\mathrm{mg} / \mathrm{kg}$ ) was 1.36 to 3.02 times higher. There was no significant difference in the time to reach peak concentration $\left(\mathrm{T}_{\max }\right)$ and the terminal half-life $\left(t_{1 / 2}\right)$ of DOX in the presence of morin.

\section{Pharmacokinetic Parameters of Intravenous DOX}

The mean plasma concentration-time profiles of DOX following intravenous administration to rats in the presence or absence of oral morin are illustrated in Fig. 2. The mean pharmacokinetic parameters of DOX are also listed in Table II. Table II shows the corresponding pharmacokinetic parameters. Compared with the control group, the presence of morin increased the AUC of DOX but was not significant. The $\mathrm{C}_{\max }$, $t_{1 / 2}$ and $T_{\max }$ of DOX were not affected by morin.

\section{Discussion}

With the great interest in herbal products as alternative medicines, much effort is currently being expended to identify natural plant compounds that modulate P-gp and metabolic enzymes. Many flavonoids including quercetin, naringin, silymarin and morin are known to modulate P-gp ${ }^{24,30,31,32)}$. In addition to the inhibition of P-gp, morin could modulate the activities of the metabolic enzymes including CYPs ${ }^{25}$. The poor bioavailability of DOX would result from the metabolism by enzymes or counter-transport processes by P-gp in the gut wall, there were some attempts to improve the oral delivery of DOX via the inhibition of P-gp and/or metabolic enzymes. However, there is little information on the pharmacokinetic

Table I-Mean ( \pm S.D.) pharmacokinetic parameters of DOX after oral administration of DOX at a dose of $50 \mathrm{mg} / \mathrm{kg}$ in the presence or absence (control) of morin at doses of $0.5,3$ and $10 \mathrm{mg} / \mathrm{kg}$ to rats ( $\mathrm{n}=6$, each)

\begin{tabular}{lcccc}
\hline \hline \multirow{2}{*}{ Parameters } & $\begin{array}{c}\text { DOX } \\
\text { (Control) }\end{array}$ & $0.5 \mathrm{mg} / \mathrm{kg}$ & DOX + Morin \\
\cline { 3 - 5 } $\mathrm{AUC}(\mathrm{ng} \cdot \mathrm{h} / \mathrm{mL})$ & $205 \pm 43.1$ & $279 \pm 57.2^{*}$ & $3 \mathrm{mg} / \mathrm{kg}$ & $10 \mathrm{mg} / \mathrm{kg}$ \\
$\mathrm{C}_{\max }(\mathrm{ng} / \mathrm{mL})$ & $21.0 \pm 4.34$ & $26.8 \pm 5.60$ & $42.2 \pm 8.82^{*}$ & $620 \pm 127^{* *}$ \\
$\mathrm{~T}_{\max }(\mathrm{h})$ & $0.33 \pm 0.13$ & $0.33 \pm 0.13$ & $0.29 \pm 0.10$ & $59.4 \pm 12.3^{* *}$ \\
$\mathrm{t}_{1 / 2}(\mathrm{~h})$ & $13.9 \pm 2.91$ & $14.8 \pm 3.11$ & $14.9 \pm 3.12$ & $0.29 \pm 0.10$ \\
$\mathrm{AB}(\%)$ & $2.7 \pm 0.55$ & $3.7 \pm 0.74^{*}$ & $6.1 \pm 1.21^{* *}$ & $15.2 \pm 3.17$ \\
$\mathrm{RB}(\%)$ & 100 & 136 & 221 & $8.3 \pm 1.70^{* *}$ \\
\hline
\end{tabular}

$* \mathrm{P}<0.05, * * \mathrm{P}<0.01$ significant difference compared with the control.

AUC: area under the plasma concentration-time curve from zero to time infinity; $\mathrm{C}_{\max }$ : peak concentration; $\mathrm{T}_{\max }$ : time to reach peak concentration; $\mathrm{t}_{1 / 2}$ : the terminal half-life; $\mathrm{AB}$ : absolute bioavailability; RB: relative bioavailability. 


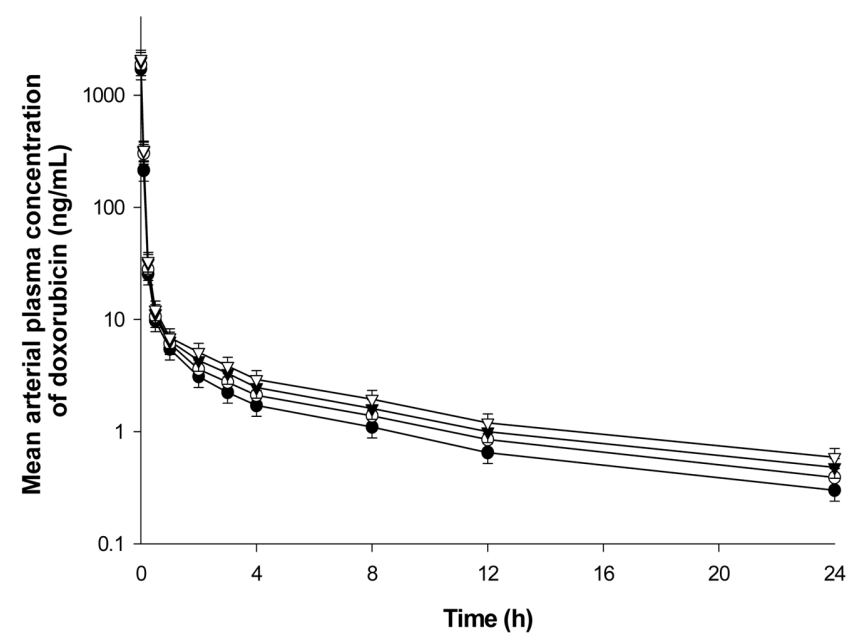

Figure 2-Mean arterial plasma concentration-time profiles of DOX after intravenous administration of DOX at a dose of $10 \mathrm{mg} / \mathrm{kg}$ in the presence of morin at doses of $0.5(\bigcirc ; n=6), 3(\nabla ; n=6)$ and 10 $\mathrm{mg} / \mathrm{kg}(\nabla ; \mathrm{n}=6)$ or absence $(\mathbf{O} ; \mathrm{n}=6)$ of morin to rats. Bars represent stnandard deviation.

interactions between DOX and morin.

Based on the broad overlap in substrate specificities as well as the co-localization in small intestine, the primary site of absorption for orally administered drugs, CYP3A and P-gp have been recognized as a concerted barrier to the drug absorption. $^{30,31)}$ Therefore, dual inhibitors against both CYP3A and Pgp could greatly impact the bioavailability of many drugs. The present study evaluated the effects of morin, a naturally occurring flavonoid, on the bioavailability of DOX in rats, to examine possible drug interactions between morin and DOX via the dual inhibition of CYP3A and P-gp.

CYP3A and P-gp inhibitors might interact with DOX and contribute to the substantial alteration of their pharmacokinetic parameters. Since cyclosporin and verapamil, both substrates for CYP3A, increased DOX plasma concentrations, it is possible that one or more enzymes of the CYP3A subfamily play a role in DOX metabolism. ${ }^{14)}$ Morin inhibited P-gp-mediated efflux of daunomycin, which was comparable to verapamil, a potent P-gp inhibitor. ${ }^{24,25)}$ It is possible that the concomitant administration of morin might affect the bioavailability or pharmacokinetics of orally administered DOX.

As shown in Table I, the presence of morin significantly increased the AUC of oral DOX. These results were consistant with the report by Buening et al ${ }^{25)}$ and Zhang and Morris, ${ }^{24)}$ suggested that the presence of morin might inhibit the CYP3A and the P-gp pathway because orally administered DOX is a substrate P-gp-mediated efflux and metabolited by CYP3A subfamily in the intestine and/or liver. Morin might be able to improve the oral bioavailability of DOX by altering its absorption pattern or reducing the gut wall metabolism of this drug. These results were consistent with the report by Choi et al. ${ }^{26}$ ) in that the presence of morin significantly increased the AUC and $\mathrm{C}_{\max }$ of paclitaxel, a P-gp and CYP3A4 substrate, in rats, and the report by $\mathrm{Li}$ et al. ${ }^{27)}$ in that morin significantly increased the AUC of etoposide in rats. Shin et al. ${ }^{28)}$ also reported that the presence of the morin at doses of 2.5 and 7.5 $\mathrm{mg} / \mathrm{kg}$ significantly increased the AUC and $\mathrm{C}_{\max }$ of tamoxifen, a P-gp and CYP3A4 substrate, in rats.

As summarized in Table II, the presence of $10 \mathrm{mg} / \mathrm{kg}$ of morin increased the AUC of intravenous DOX but was not significant. Morin had no effect on other pharmacokinetic parameters of intravenous DOX, although it exhibited a significant effect on the bioavailability of oral DOX. This result is similar to a report by $\mathrm{Li} e \mathrm{al}^{27)}$ showing that the presence of morin did not increase the AUC of intravenous etoposide in rats. Total body clearance of DOX was not affected by morin after intravenous administration. This result suggested that increased AUC of DOX was not related to elimination. Collectively, the bioavailability of oral DOX was significantly increased by the concomitant use of morin via the inhibition of the P-gp mediated efflux and first-pass metabolism of DOX in the intestine and/or liver. This result may suggest that the development of oral DOX preparations as a combination with

Table II-Mean ( \pm S.D.) pharmacokinetic parameters of DOX after intravenous administration of DOX at a dose of $10 \mathrm{mg} / \mathrm{kg}$ in the presence or absence (control) of morin at doses of $0.5,3$ and $10 \mathrm{mg} / \mathrm{kg}$ to rats $(n=6$, each)

\begin{tabular}{lcccc}
\hline \hline \multirow{2}{*}{ Parameters } & \multirow{2}{*}{$\begin{array}{c}\text { DOX } \\
\text { (Control) }\end{array}$} & $0.5 \mathrm{mg} / \mathrm{kg}$ & $3 \mathrm{mg} / \mathrm{kg}$ & $10 \mathrm{mg} / \mathrm{kg}$ \\
\hline AUC $(\mathrm{ng} \cdot \mathrm{h} / \mathrm{mL})$ & $1498 \pm 312$ & $1765 \pm 367$ & $1878 \pm 387$ & $1992 \pm 406$ \\
$\mathrm{CL}_{\mathrm{t}}(\mathrm{mL} / \mathrm{min} / \mathrm{kg})$ & $25.0 \pm 5.23$ & $29.4 \pm 6.09$ & $31.3 \pm 6.47$ & $32.1 \pm 6.82$ \\
$\mathrm{t}_{1 / 2}(\mathrm{~h})$ & $8.12 \pm 1.70$ & $8.37 \pm 1.73$ & $8.61 \pm 1.80$ & $8.83 \pm 1.82$ \\
$\mathrm{RB}$ & 100 & 118 & 125 & 133 \\
\hline
\end{tabular}

$* \mathrm{P}<0.05$, significant difference compared with the control.

AUC: area under the plasma concentration-time curve from zero to infinity; $\mathrm{CL}_{\mathrm{t}}$ : total body clearance; $\mathrm{t}_{1 / 2}$ : terminal half-life; RB: relative bioavailability. 
morin is feasible, which is more convenient than the i.v. dosage forms.

\section{Conclusion}

The presence of morin enhanced the oral bioavailability of DOX, which might be attributed to the promotion of intestinal absorption and a reduction of the first-pass metabolism of DOX in the intestine. This result may suggest that the development of oral DOX preparations as a combination with morin is feasible, which is more convenient than the i.v. dosage forms.

\section{References}

1) C. Avendano and J. C.Menendez, Inhibitors of multidrug resistance to antitumor agents (MDR), Curr. Med. Chem., 9, 159193 (2002).

2) M.M. Gottesman, T. Fojo and S.E. Bates, Multidrug resistance in cancer: role of ATP-dependent transporters, Nat. Rev. Cancer., 2, 48-58 (2002).

3) C. Cordon-Cardo, J.P. O'Brien, D. Casals, J.R. Bertino and M. R. Melamed, Expression of the multidrug resistance gene product (P-glycoprotein) in human normal and tumor tissues, J. Histochem. Cytochem., 38, 1277-1287 (1990).

4) A.T. Fojo, D.W. Shen, L.A. Mickley, I. Pastan and M.M. Gottesman, Intrinsic drug resistance in human kidney cancer is associated with expression of a human multidrug-resistance gene, J. Clin. Oncol., 5, 1922-1927 (1987).

5) D.E. Merkel, S.A.W. Fuqua, A.K. Tandom, S.M. Hill, A.U. Buzdar and W.L. McGuire, Electrophoretic analysis of 248 clinical breast cancer specimens for P-glycoprotein overexpression of gene amplification, J. Clin. Oncol., 7, 1129-1136 (1989).

6) E. Wang, K. Lew, M. Barecki, C.N. Casciano, R.P. Clement and W.W. Johnson, Quantitative distinctions of active site molecular recognition by $\mathrm{P}$-glycoprotein and cytochrome $\mathrm{P} 450$ 3A4, Chem. Res. Toxicol., 14, 1596-1603 (2001).

7) M. Fakhoury, C. Litalien, Y. Medard, H. Cave, N. Ezzahir, M. Peuchmaur and E. Jacqz-Aigrain, Localization and mRNA expression of CYP3A and P-glycoprotein in human duodenum as a function of age, Drug Metab. Dispos., 33, 1603-1607 (2005).

8) M.H. Schwarzbach, S. Eisold, T. Burguete, F. Willeke, P. Klein-Bauernschmitt, J.R. Schlehofer, C. Herfarth, R. Ridder and von M. Knebel Doeberitz, Sensitization of sarcoma cells to doxorubicin treatment by concomitant wildtype adeno-associated virus type 2 (AAV-2) infection, Int. J. Oncol., 20, 12111218 (2002).

9) F. Langer, H.O. Wintzer, M. Werner, C. Weber, T.H. Brummendorf and C.A Bokemeyer, Case of pulmonary carcinosarcoma (squamous cell carcinoma and osteosarcoma) treated with cisplatin and doxorubicin, Anticancer Res., 26, 38933897 (2006).

10) P.A. Lind, G. Naucler, A. Holm, M. Gubanski and C. Svensson, Efficacy of pegylated liposomal doxorubicin in patients with advanced hepatocellular carcinoma, Acta. Oncol., 46, 230-233 (2007).

11) B.B. Lundberg, G. Griffiths and H.J. Hansen, Cellular association and cytotoxicity of doxorubicin-loaded immunoliposomes targeted via Fab' fragments of an anti-CD74 antibody, Drug Deliv., 14, 171-175 (2007).

12) M.G. Smylie, R. Wong, C. Mihalcioiu, C. Lee and J.F. Pouliot, A phase II, open label, monotherapy study of liposomal doxorubicin in patients with metastatic malignant melanoma, Invest. New Drugs., 25, 155-159 (2007).

13) D.L. Gustafson, A.L. Merz and M.E. Long, Pharmacokinetics of combined doxorubicin and paclitaxel in mice, Cancer Lett., 220,161-169 (2005).

14) K.T. Kivistö, H.K. Kroemer and M. Eichelbaum, The role of human cytochrome P450 enzymes in the metabolism of anticancer agents: implications for drug interactions, Br. J. Clin. Pharmacol., 40, 523-v530 (1995).

15) E. Jr. Middleton, C. Kandaswami and T. Theoharides, The effects of plant flavonoids on mammalian cells: implications for inflammation, heart disease, and cancer, Pharmacol. Rev., 52, 673-751 (2000).

16) H. Lee, H.W. Wang, H.Y. Su and N.J. Hao, The structure-activity relationships of flavonoids as inhibitors of cytochrome P450 enzymes in rat liver microsomes and the mutagenicity of 2-amino-3-methyl-imidazo[4, 5-f]quinoline, Mutagenesis., 9, 101-106 (1994).

17) E. Chieli, N. Romiti, F. Cervelli and R. Tongiani, Effects of flavonols on P-glycoprotein activity in cultured rat hepatocytes, Life Sci., 57, 1741-1751 (1995).

18) A. Di Pietro, G. Conseil, J. M. Perez-Victoria, G. Dayan, H. Baubichon-Cortay, D. Trompier, E. Steinfels, J. M. Jault, H. de Wet, M. Maitrejean, G. Comte, A. Boumendjel, A.M. Mariotte, C. Dumontet, D.B. McIntosh, A. Goffeau, S. Castanys, F. Gamarro and D. Barron, Modulation by flavonoids of cell multidrug resistance mediated by P-glycoprotein and related ABC transporters, Cell. Mol. Life Sci., 59, 307-322 (2002).

19) L.D. Kok, Y.P. Wong, T.W. Wu, H.C. Chan, T.T. Kwok and K.P. Fung, Morin hydrate: a potential antioxidant in minimizing the free-radicals-mediated damage to cardiovascular cells by anti-tumor drugs, Life Sci., 67, 91-99 (2000).

20) A.R. Francis, T.K. Shetty and R.K. Bhattacharya, Modulating effect of plant flavonoids on the mutagenicity of N-methyl-N'nitro-N-nitrosoguanidine, Carcinogenesis. 10, 1953-1955 (1989).

21) S.H. Fang, Y.C. Hou, W.C. Chang, S.L. Hsiu, P.D. Chao and B.L. Chiang, Morin sulfates/glucuronides exert anti-inflammatory activity on activated macrophages and decreased the incidence of septic shock, Life Sci., 74, 743-756 (2003).

22) S.L. Hsiu, C.W. Tsao, Y.C. Tsai, H.J. Ho and P.D. Chao, Determinations of morin, quercetin and their conjugate metabolites in serum, Biol. Pharm. Bull., 24, 967-969 (2001). 
23) Y.C. Hou, P.D. Chao, H.J. Ho, C.C. Wen and S.L. Hsiu, Profound difference in pharmacokinetics between morin and its isomer quercetin in rats, J. Pharm. Pharmacol. 55, 199-203 (2003).

24) S. Zhang and M.E. Morris, Effects of the flavonoids biochanin A, morin, phloretin, and silymarin on P-glycoprotein-mediated transport, J. Pharmacol. Exp. Ther., 304, 1258-1267 (2003).

25) M.K. Buening, R.L. Chang, M.T. Huang, J.G. Fortner, A.W Wood and A.H. Conney, Activation and inhibition of benzo (a) pyrene and aflatoxin B1 metabolism in human liver microsomes by naturally occurring flavonoids, Cancer Res. 41, 67-72 (1981).

26) B.C. Choi, J.S. Choi and H.K. Han, Altered pharmacokinetics of paclitaxel by the concomitant use of morin in rats, Int. $J$. Pharm., 323, 81-85 (2006).

27) X. Li, J.K. Yun and J.S. Choi, Effects of morin on the pharmacokinetics of etoposide in rats.. Biopharm, Drug Dispos., 28, 151-156 (2007).

28) S.C. Shin, Y.J. Piao and J.S. Choi, Effects of morin on the bioavailability of tamoxifen and its main metabolite, 4-hydroxytamoxifen, in rats, In Vivo., 22, 391-395 (2008).

29) A. Andersen, D.J. Warren and L. Slordal, A sensitive and simple high-performance liquid chromatographic method for the determination of doxorubicin and its metabolites in plasma,
Ther. Drug Monit., 15, 455-461 (1993).

30) C.L. Cummins, W. Jacobsen and L.Z. Benet, Unmasking the dynamic interplay between intestinal P-glycoprotein and CYP3A4, J. Pharmacol. Exp. Ther., 300, 1036-1045 (2002).

31) L.Z. Benet, C.L. Cummins and C.Y. Wu, Transporter-enzyme interactions: implications for predicting drug-drug interactions from in vitro data, Curr. Drug Metab., 4, 393-398 (2003).

30) J.W. Critchfield, C.J. Welsh, J.M. Phang and G.C. Yeh, Modulation of adriamycin accumulation and efflux by flavonoids in HCT-15 colon cells. Activation of P-glycoprotein as a putative mechanism, Biochem. Pharmacol., 48, 1437-1445 (1994).

31) G. Scambia, F.O. Ranellett, P.B. Panici, D.R. Vincenzo, G. Bonanno, G. Frrandina, M. Piantelli, S. Bussa, C. Rumi and M. Ciantriglia, Quercetin potentiates the effect of adriamycin in a multidrug-resistant MCF-7 human breast-cancer cell line: Pglycoprotein as a possible target, Cancer Chemother. Pharmacol., 36, 448-450 (1994).

32) V.A. Eagling, L. Profit and D.J. Back, Inhibition of the CYP3A4-mediated metabolism and P-glycoprotein-mediated transport of the HIV-1 protease inhibitor saquinavir by grapefruit juice components, Br. J. Clin. Pharmacol., 48, 543-552 (1999). 